\title{
Brief Report: Sensorimotor Gating in Idiopathic Autism and Autism Associated with Fragile X Syndrome
}

\author{
Jennifer Yuhas $\cdot$ Lisa Cordeiro $\cdot$ Flora Tassone $\cdot$ \\ Elizabeth Ballinger • Andrea Schneider · James M. Long • \\ Edward M. Ornitz • David Hessl
}

Published online: 3 June 2010

(C) The Author(s) 2010. This article is published with open access at Springerlink.com

\begin{abstract}
Prepulse inhibition (PPI) may useful for exploring the proposed shared neurobiology between idiopathic autism and autism caused by FXS. We compared PPI in four groups: typically developing controls $(n=18)$, FXS and autism (FXS+A; $n=15)$, FXS without autism spectrum disorder (FXS $-\mathrm{A} ; n=17$ ), and idiopathic autism (IA; $n=15)$. Relative to controls, the FXS $+\mathrm{A}(\mathrm{p}<0.002)$ and FXS - A $(p<0.003)$ groups had impaired PPI. The FXS + A
\end{abstract}

J. Yuhas $\cdot$ L. Cordeiro $\cdot$ E. Ballinger $\cdot$ A. Schneider .

D. Hessl $(\bowtie)$

Medical Investigation of Neurodevelopmental Disorders

(M.I.N.D.) Institute, University of California-Davis, Medical

Center, 2825 50th street, Sacramento, CA 95817, USA

e-mail: david.hessl@ucdmc.ucdavis.edu

A. Schneider · D. Hessl

Department of Psychiatry and Behavioral Sciences, University

of California-Davis, Medical Center, Sacramento, CA, USA

F. Tassone

Department of Biochemistry and Molecular Medicine,

University of California-Davis, Medical Center, Sacramento,

CA, USA

J. M. Long

James Long Company, Caroga Lake, NY, USA

E. M. Ornitz

Department of Psychiatry and Biobehavioral Sciences and Brain Research Institute, University of California- Los Angeles, Los Angeles, CA, USA

Present Address:

J. Yuhas

Yale School of Medicine, New Haven, CT, USA

Present Address:

L. Cordeiro

University of Denver, Denver, CO, USA $(\mathrm{p}<0.01)$ and FXS-A $(\mathrm{p}<0.03)$ groups had lower PPI than the IA group. Prolonged startle latency was seen in the IA group. The differing PPI profiles seen in the FXS $+\mathrm{A}$ and IA indicates these groups may not share a common neurobiological abnormality of sensorimotor gating.

Keywords PPI $F M R 1$ gene - Sensorimotor gating · mGluR5 $\cdot$ Prepulse inhibition $\cdot$ Startle

Fragile X syndrome (FXS) is the most common inherited form of intellectual disability and the leading known cause of autism. FXS results from a trinucleotide repeat expansion, leading to a decrease of the FMRI protein (FMRP). FMRP moderates RNA transcription and directly influences many other proteins, and diminished FMRP results in aberrant brain development. Consequently, individuals with FXS display a phenotype characterized by cognitive impairment, social and communication deficits, stereotypic behavior, gaze aversion, attention deficits, hyperactivity, aggression, hyperarousal, and sensory abnormalities.

Individuals with idiopathic autism also demonstrate many of these behavioral, social, and sensory abnormalities. The rate of FXS in those with autism varies from 2 to 8\% when utilizing DNA testing (Estecio et al. 2002; Wassink et al. 2001). The reported prevalence of autism within the FXS population has ranged from 15 to $33 \%$ (Bailey et al. 2001; Harris et al. 2008; Reiss and Freund 1992; Rogers et al. 2001), and 30\% meet criteria for a diagnosis of Pervasive Developmental Disorder-Not Otherwise Specified (PDD-NOS). Additionally, 50-90\% of individuals with FXS have significant autistic-like behaviors (such as gaze avoidance, stereotypies, etc.) even without meeting formal diagnostic criteria for PDD-NOS or autism. The large overlap in phenotypic profiles between 
Fig. 1 Summary of initial study enrollment and breakdown to number of subjects included in the final analyses

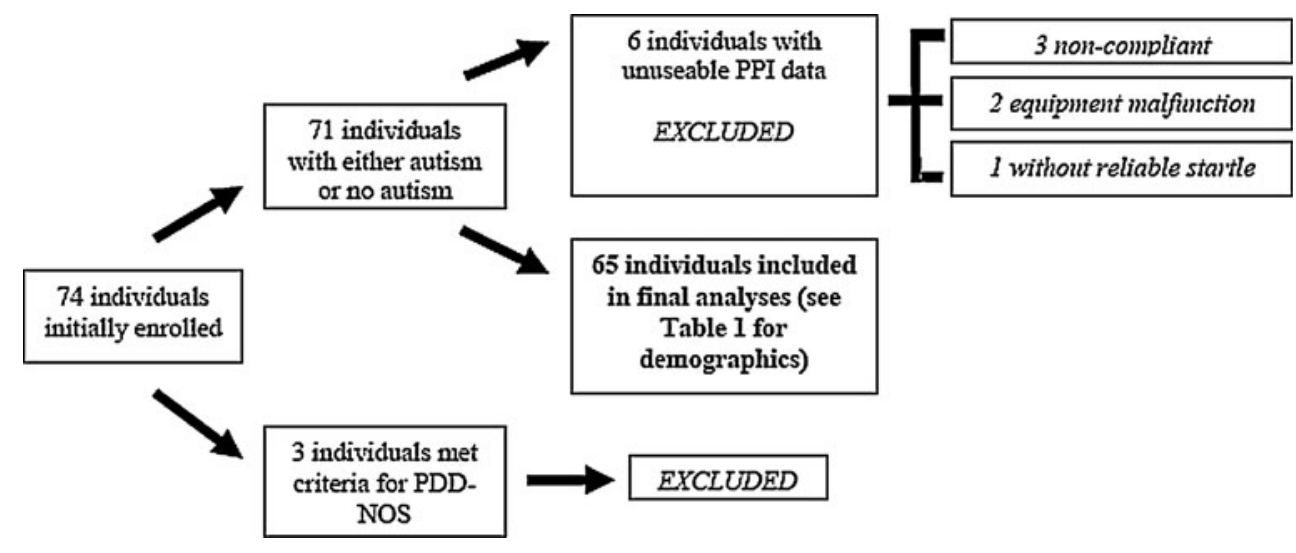

the two groups has led to a hypothesis that FXS and autism may share a common neurobiology.

Pre-pulse inhibition (PPI) is a well-documented indicator of sensorimotor gating, a process important for filtering extraneous sensory information from the external environment. PPI is an objective measure of the attenuation of a startle response to an intense auditory stimulus, when that stimulus is preceded by an innocuous tone. PPI is mediated through a neurological pathway involving the pontine brainstem, which receives modulatory input from the prefrontal cortex, hippocampus, and amygdala as these structures converge on the nucleus accumbens (Schmajuk and Larrauri 2005). PPI is regulated by many neurotransmitter systems, including the glutamatergic receptor pathways such as the mGluR (Zou et al. 2007), GABA (Arai et al. 2008; Bortolato et al. 2007; Fendt 1999; Kodsi and Swerdlow 1995), and NMDAR receptor systems (Wolf et al. 2007).

A PPI deficit in males with FXS was first demonstrated by Frankland and colleagues (2004), and subsequently replicated by our laboratory in a larger sample of males and females (Hessl et al. 2008). PPI impairment in high functioning autism or Asperger's Disorder has been reported and associated with inhibitory control problems (McAlonan et al. 2002) or restricted and repetitive behaviors (Perry et al. 2007). However, an earlier study was unable to demonstrate a significant PPI deficit in high and lowfunctioning individuals with autism (Ornitz et al. 1993).

The aim of the current study was to directly compare PPI in individuals with FXS (with and without autism) with individuals with idiopathic autism as well as typicallydeveloping controls, to uncover potential commonalities in the neurobiological processes underlying the shared phenotypic characteristics.

\section{Methods}

Seventy-one individuals were enrolled and were divided into four groups based on their clinical diagnoses: fragile $\mathrm{X}$ with autism $(\mathrm{FX}+\mathrm{A})$, fragile $\mathrm{X}$ without autism $(\mathrm{FX}-\mathrm{A})$, idiopathic autism (IA), or typically developing control (C). Participants were consecutive clinic referrals or enrolled through the M.I.N.D. Institute recruitment sources. Study enrollment and final group demographics can be seen in Fig. 1 and Table 1, respectively. Individuals were agematched across all groups, and individuals in the FXS+A and IA groups were also IQ matched.

Thirteen of the individuals included in the final analyses were previously reported in Hessl et al. 2008 (8 FX-A, 3 $\mathrm{FX}+\mathrm{A}, 2 \mathrm{C}$ ). Psychoactive medication use by subjects in each group is shown in Table 2.

Exclusion criteria included known hearing loss, facial motor tics, and central nervous system involvement other than autism or FXS (e.g., cerebral palsy, fetal alcohol syndrome, or serious head injury). In addition, control subjects were excluded if they had any history of psychiatric diagnoses or learning disabilities.

Fragile $\mathrm{X}$ full mutation status was confirmed through FMRI DNA testing using PCR and Southern Blot as described in Tassone et al. (2008), and all participants in the IA group were confirmed negative. Autistic Disorder was determined using the Autism Diagnostic Observation Schedule (Lord et al. 2002) and DSM-IV criteria. When possible, the Autism Diagnostic Interview (Lord et al. 1994) and Social Communication Questionnaire (Rutter et al. 2003) were utilized to help confirm diagnosis. Only those individuals meeting criteria for full Autistic Disorder or no autism were included in the final study groups.

Table 1 Summary of participant demographics in each study group, including age and gender breakdown

\begin{tabular}{lccclc}
\hline Group & $\mathrm{N}$ & $\begin{array}{l}\text { Males } \\
(\mathrm{N})\end{array}$ & $\begin{array}{l}\text { Females } \\
(\mathrm{N})\end{array}$ & $\begin{array}{l}\text { Age (Mean, } \\
\text { range })\end{array}$ & $\begin{array}{l}\text { IQ (Mean, } \\
\mathrm{SD})\end{array}$ \\
\hline FXS-A & 17 & 4 & 13 & $15.49(11-23)$ & $68.65,15.2$ \\
FXS+A & 15 & 13 & 2 & $17.04(10-24)$ & $55.07,3.9$ \\
IA & 15 & 13 & 2 & $16.83(14-23)$ & $56.47,6.6$ \\
C & 18 & 11 & 7 & $16.61(11-24)$ & $119.17,11.3$ \\
\hline
\end{tabular}


Table 2 Summary of the number of participants in each clinical group taking different types of medication at the time of testing

\begin{tabular}{lllllllll}
\hline Group $(n)$ & No medication & SSRI/SNRI & Anti- psychotics & Stimulants & Anti- convulsants & $\begin{array}{l}\text { Anti-anxiety } \\
\text { Sedatives }\end{array}$ & $\begin{array}{l}\text { Other } \\
\text { antidepressants }\end{array}$ \\
\hline FXS-A (17) & 6 & 8 & 4 & 3 & 0 & 1 & 0 & 2 \\
FXS+A (15) & 5 & 7 & 3 & 4 & 0 & 2 & 0 & 1 \\
IA (14) & 4 & 5 & 4 & 1 & 2 & 0 & 0 & 0 \\
C (18) & 18 & 0 & 0 & 0 & 0 & 0 & 0 & 0 \\
\hline
\end{tabular}

The PPI data collection and videocoding followed the protocol previously described in detail (Hessl et al. 2008). Trial types consisted of $105 \mathrm{db}$ white noise startle stimuli (SS) or prepulse trials consisting of $25 \mathrm{~ms}, 75 \mathrm{db}, 1 \mathrm{kHz}$ tones occurring 60,120 , or $240 \mathrm{~ms}$ prior to the SS. The trial order was random, and inter-trial intervals ranged from 25 to $45 \mathrm{~s}$. EMG startle data was visually scrutinized, and the validity of each trial was confirmed using standardized videocoding of behavior prior to data analysis as previously described.

A $\log$ transformation of the data was employed to normalize the distributions for subsequent analyses. Percent PPI for each prepulse trial type was calculated using following equation: $100 \mathrm{X}$ [(response amplitude in the startle stimulus alone trials-response amplitude in the prepulse trials)/response amplitude in the startle stimulus alone trials].

\section{Results}

Mean startle amplitude to the SS (no prepulse) was compared across groups (Table 3). Analysis of variance (ANOVA) showed no significant between group differences, $\mathrm{F}(3,53)=0.29, \mathrm{p}=0.83$.

Startle latency to the SS showed positive skew with notable outliers. Transformation of the data was not successful, and therefore group differences were analyzed using non-parametric tests. A Kruskal-Wallis test revealed a main effect of group, $p=0.001$. Pairwise group comparisons showed that the IA group had a longer latency than each of the other three groups (all $\mathrm{p}<0.01$; Fig. 2).

For PPI, a repeated measures ANOVA, with prepulse interval type as the repeating dependent variable and group as the independent variable revealed main effects of trial type $[F(2)=9.22, p<0.001]$ and group $[F(3,59)=5.63$, $\mathrm{p}=0.002]$. Post-hoc pairwise comparisons (Fisher's LSD) showed that participants with FXS+A $(\mathrm{p}=0.002)$ and FXS $-A(p=0.003)$ had lower PPI than $C$. In addition, the FXS $-A(p=0.03)$ and FXS+A $(p=0.01)$ groups had lower PPI than the IA group. All other group comparisons and group by trial type interactions were non-significant, including the comparison between the IA and $\mathrm{C}$ groups
(Fig. 3 and Table 3). There was a consistent trend across all interval trial types with PPI increasing from FXS-A to FXS +A to IA to controls.

As noted in the participant descriptions, gender ratios across groups were not equivalent, especially within the $\mathrm{FXS}+\mathrm{A}$ (higher proportion of males) and FXS $-\mathrm{A}$ (higher proportion of females). Because different gender ratios may confound observed differences between groups, we analyzed PPI group differences for males only for IA $(n=9), \mathrm{FXS}+\mathrm{A}(n=11)$, and $\mathrm{C}(n=10)$ groups, using non-parametric tests. A Kruskal-Wallis test revealed a main effect of group for the 60,120 , and $240 \mathrm{~ms}$ intervals $(\mathrm{p}=0.03, \mathrm{p}=0.007$, and $\mathrm{p}=0.006$, respectively). Pairwise group comparisons with Mann-Whitney tests demonstrated significant differences between $\mathrm{C}$ and FXS+A ( $\mathrm{p}<0.01$ for all intervals) and between IA and FXS+A groups for the 120 and $240 \mathrm{~ms}$ intervals $(\mathrm{p}=0.02$ and $\mathrm{p}=0.02$, respectively; Fig. 4). All three groups were matched on age $(\mathrm{IA}=17.1, \quad \mathrm{FXS}+\mathrm{A}=17.5$, and $\mathrm{C}=16.61$ years). The IA and FXS $+\mathrm{A}$ groups were additionally matched on IQ $(\mathrm{IA}=56.3$ and $\mathrm{FXS}+\mathrm{A}=54.6)$.

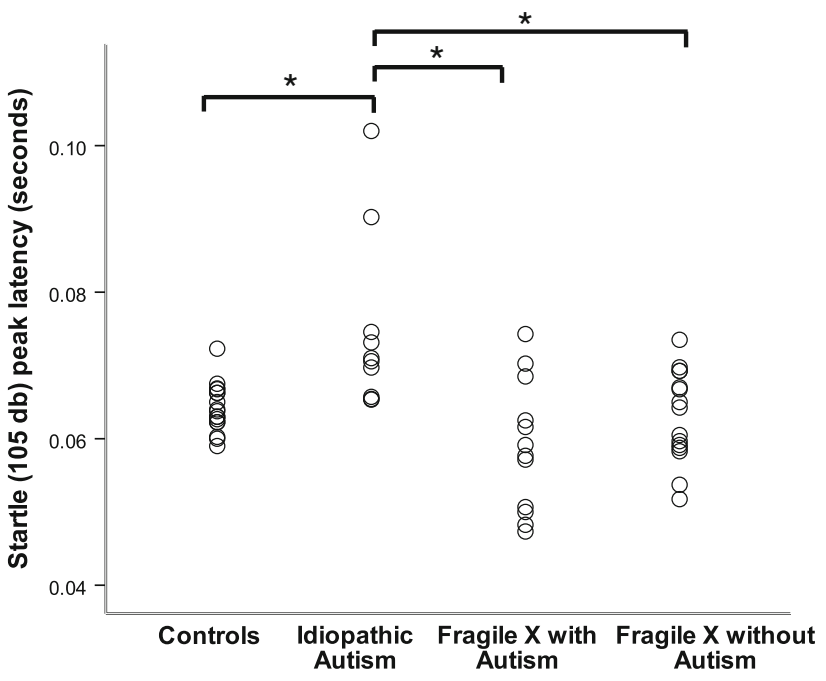

Fig. 2 Latency of peak startle response by group (including males and females). Nonparametric tests revealed a longer latency in the idiopathic autism group relative to the typical control $(p<0.001)$, FXS with autism $(\mathrm{p}<0.002)$ and FXS without autism $(\mathrm{p}<0.004)$ groups. All groups were age-matched, and the FXS + A and IA groups were IQ-matched 
Fig. 3 Prepulse inhibition (PPI) in each group (including males and females), by prepulse interval trial type.

$\mathrm{C}=$ Typically developing controls, IA = Idiopathic Autism, FXS $+\mathrm{A}=$ fragile $\mathrm{X}$ syndrome with autism, FXS$\mathrm{A}=$ fragile $\mathrm{X}$ syndrome without autism. PPI was significantly lower in FXS+A $(\mathrm{p}=0.002)$ and $\mathrm{FXS}-\mathrm{A}$ $(\mathrm{p}=.003)$ compared with controls. PPI was also significantly lower in $\mathrm{FXS}+\mathrm{A}$ $(\mathrm{p}=.01)$ and $\mathrm{FXS}-\mathrm{A}$

$(\mathrm{p}=.03)$ compared to IA

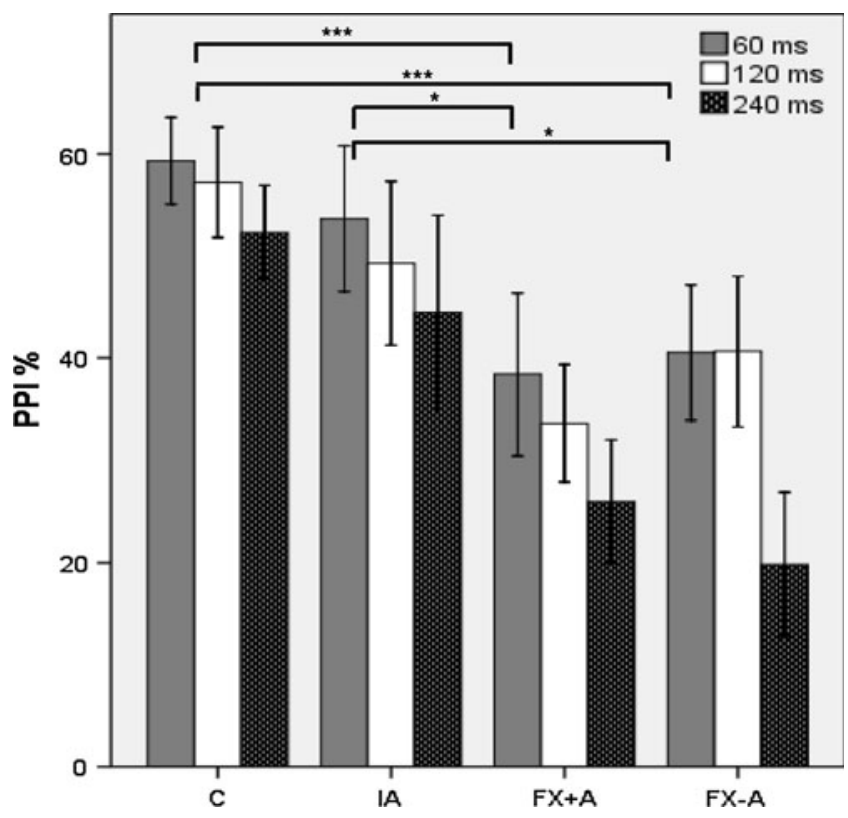

who demonstrated similar behavioral and cognitive profiles but differed markedly in the volumes of specific brain regions (Cody-Hazlett et al. 2009). More robust sample sizes are needed to further investigate whether subtypes exist in IA populations with regard to PPI performance.

Gender was identified as a potential confounder in this investigation. Nonetheless, we were able to demonstrate significant differences between the two groups with autism in males only. Study groups with a more equal gender distribution (i.e. greater numbers of males with FXS-A or females with $\mathrm{FXS}+\mathrm{A}$ or IA) would provide more reliable contrasts in PPI across these groups of interest.

Many of our study participants were taking psychoactive medications at the time of data collection. Although the sample size was too small to examine effects of specific types of medications, we found no significant differences in PPI between those taking and not taking medications at the time of testing (data not shown). A more thorough examination of the potential impact of psychoactive medications on PPI performance in FXS can be found in Hessl et al. (2008).

Table 3 Descriptive statistics of the amplitude of startle response to stand-alone startle stimulus (in $\mathrm{mV}$ ) and prepulse inhibition (PPI; \% inhibition) in individuals with FXS-A, FXS +A, IA and controls; descriptive statistics of PPI are further broken down by prepulse interval

\begin{tabular}{|c|c|c|c|c|c|c|c|c|}
\hline & \multicolumn{2}{|c|}{$\mathrm{FXS}-\mathrm{A}(n=17)$} & \multicolumn{2}{|c|}{$\mathrm{FXS}+\mathrm{A}(n=15)$} & \multicolumn{2}{|c|}{ IA $(n=15)$} & \multicolumn{2}{|c|}{$\mathrm{C}(n=18)$} \\
\hline & Mean & SD & Mean & SD & Mean & SD & Mean & SD \\
\hline $105 \mathrm{~dB}$ SS $(\mathrm{mV})$ & 101.71 & 54.8 & 94.64 & 91.98 & 90.17 & 71.61 & 95.99 & 75.64 \\
\hline \multicolumn{9}{|c|}{ Prepulse interval (\%) } \\
\hline $60 \mathrm{~ms}$ & 30.11 & 26.95 & 38.55 & 24.44 & 50.43 & 22.30 & 60.25 & 17.43 \\
\hline $120 \mathrm{~ms}$ & 33.75 & 28.76 & 35.00 & 21.07 & 47.94 & 23.61 & 58.49 & 22.30 \\
\hline $240 \mathrm{~ms}$ & 8.21 & 34.93 & 29.36 & 20.80 & 38.16 & 28.56 & 53.63 & 19.30 \\
\hline
\end{tabular}




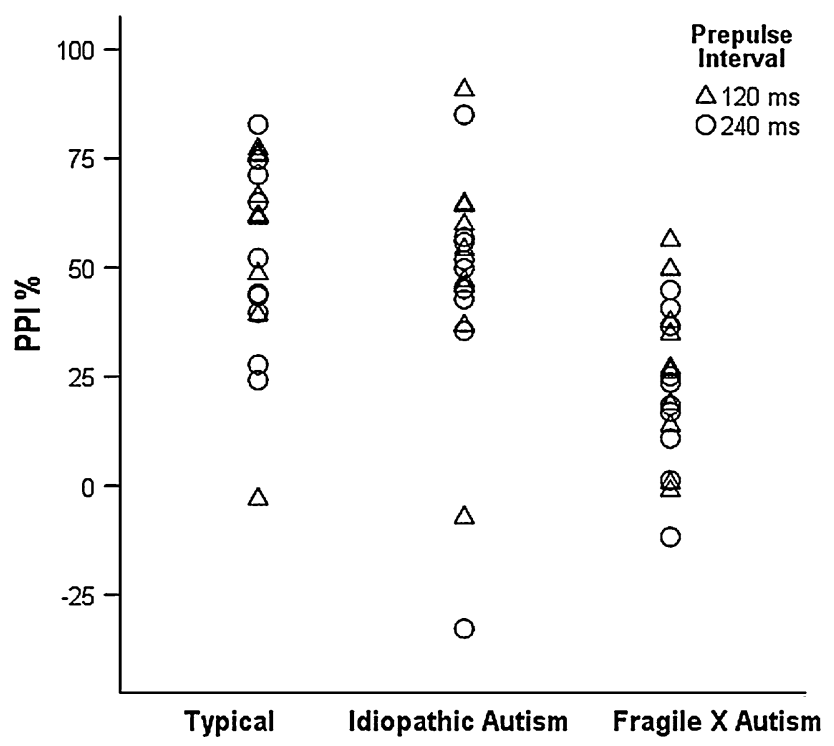

Fig. 4 PPI \% in males with idiopathic autism (IA), fragile $X$ with autism $(\mathrm{FXS}+\mathrm{A})$, and typically developing controls (C). All three groups were matched on age, and the two autism groups were additionally matched on IQ. Males with fragile X with autism had significantly impaired PPI relative to both controls $(\mathrm{p}<0.01)$ and males with idiopathic autism $(\mathrm{p}<0.05)$

Significant differences in startle latency were found between the idiopathic autism group and the fragile $\mathrm{X}$ groups, as well as typically developing controls. Ornitz et al. (1993) found longer latency to auditory stimuli in autism relative to controls, though this effect did not reach statistical significance. The longer startle latency in idiopathic autism may be associated with disruption of the basic startle reflex pathway involving primarily brain stem circuits, such as the auditory brainstem response abnormalities in autism previously reported (Fujikawa-Brooks et al. 2010) .

We were unable to document a significant PPI deficit in our idiopathic autism group. Although the prior research of Perry et al. (2007) and McAlonan et al. (2002) showed PPI deficits associated with autism, these studies included higher functioning adults with autism or Asperger's Disorder, whereas our sample included much lower functioning children and adolescents. The only prior work which studied PPI in low-functioning individuals with autism was conducted by Ornitz et al. (1993). That study, which included a cohort of individuals with both high- and lowfunctioning individuals with autism, revealed no significant PPI deficit. The inconsistency in PPI results may be explained by autism cohort or protocol differences such as type and intensity of prepulse and startle stimuli. Again, larger sample sizes in future studies may be necessary to reveal true deficits in PPI that may exist in children with autism, or specific subgroups.
The mGluR theory of FXS postulates that upregulation of mGluR5-mediated activity seen in the absence of FMRP may contribute to the clinical features of the disorder. In animal studies, mGluR5 negative modulators have been shown to rescue behavioral, cognitive, and prepulse inhibition deficits in fmr1 knockout fruit fly and mouse models (de Vrij et al. 2008; Dolen et al. 2007; McBride et al. 2005; Yan et al. 2005). As such, clinical trials employing the use of similar mGluR5 antagonists have moved to the forefront of research efforts to produce clinical improvements in humans with FXS. If mGluR dysregulation plays a role in sensorimotor gating deficits in FXS, it may also play a similar role a subset of individuals with IA demonstrating PPI deficits. Thus, demonstration of the commonalities in the neurobiological processes underlying PPI deficits between individuals from phenotypically-related clinical groups may have implications for future collaboration in targeted treatment efforts.

Acknowledgments We are grateful to the research participants and their families; Louise Gane for her assistance with recruitment; Alyssa Chavez for her help with data entry and management and Maisha Ollison for her assistance with data entry and coding. Funding from the National Institutes of Health Grants MH77554 (D.H.), HD055510 (F.T.); a M.I.N.D. Institute Pilot Grant (D.H.) supported this work.

Open Access This article is distributed under the terms of the Creative Commons Attribution Noncommercial License which permits any noncommercial use, distribution, and reproduction in any medium, provided the original author(s) and source are credited.

\section{References}

Arai, S., Takuma, K., Mizoguchi, H., Ibi, D., Nagai, T., Takahashi, $\mathrm{K}$., et al. (2008). Involvement of pallidotegmental neurons in methamphetamine- and MK-801-induced impairment of prepulse inhibition of the acoustic startle reflex in mice: Reversal by GABA(B) receptor agonist baclofen. Neuropsychopharmacology, 33, 3164-3175.

Bailey, D. B., Jr., Hatton, D. D., Skinner, M., \& Mesibov, G. (2001). Autistic behavior, FMR1 protein, and developmental trajectories in young males with fragile $\mathrm{X}$ syndrome. Journal of Autism and Developmental Disorders, 31(2), 165-174.

Bortolato, M., Frau, R., Orru, M., Piras, A. P., Fa, M., Tuveri, A., et al. (2007). Activation of $\operatorname{GABA}(\mathrm{B})$ receptors reverses spontaneous gating deficits in juvenile DBA/2 J mice. Psychopharmacology (Berl), 194(3), 361-369.

Cody-Hazlett, H. C., Poe, M. D., Lightbody, A. A., Guido, G., MacFall, J. R., Ross, A. K., et al. (2009). Teasing apart the heterogeneity of autism: Same behavior, different brains in toddlers with fragile $\mathrm{X}$ syndrome and autism. Journal of Neurodevelopmental Disorders, 1, 81-90.

de Vrij, F. M., Levenga, J., van der Linde, H. C., Koekkoek, S. K., De Zeeuw, C. I., Nelson, D. L., et al. (2008). Rescue of behavioral phenotype and neuronal protrusion morphology in Fmr1 KO mice. Neurobiology of Diseases, 31(1), 127-132.

Dolen, G., Osterweil, E., Rao, B. S., Smith, G. B., Auerbach, B. D., Chattarji, S., et al. (2007). Correction of fragile X syndrome in mice. Neuron, 56(6), 955-962. 
Estecio, M., Fett-Conte, A. C., Varella-Garcia, M., Fridman, C., \& Silva, A. E. (2002). Molecular and cytogenetic analyses on Brazilian youths with pervasive developmental disorders. Journal of Autism and Developmental Disorders, 32(1), 35-41.

Fendt, M. (1999). Enhancement of prepulse inhibition after blockade of GABA activity within the superior colliculus. Brain Research, 833(1), 81-85.

Frankland, P. W., Wang, Y., Rosner, B., Shimizu, T., Balleine, B. W., Dykens, E. M., et al. (2004). Sensorimotor gating abnormalities in young males with fragile $\mathrm{X}$ syndrome and Fmr1-knockout mice. Molecular Psychiatry, 9(4), 417-425.

Fujikawa-Brooks, S., Isenberg, A. L., Osann, K., Spence, M. A., \& Gage, N. M. (2010). The effect of rate stress on the auditory brainstem response in autism: A preliminary report. International Journal of Audiology, 49(2), 129-140.

Harris, S. W., Hessl, D., Goodlin-Jones, B., Ferranti, J., Bacalman, S., Barbato, I., et al. (2008). Autism profiles of males with fragile X syndrome. American Journal of Mental Retardation, 113(6), 427-438.

Hessl, D., Berry-Kravis, E., Cordeiro, L., Yuhas, J., Ornitz, E. M., Campbell, A., et al. (2008). Prepulse inhibition in fragile X syndrome: Feasibility, reliability, and implications for treatment. American Journal of Medical Genetics. Part B, Neuropsychiatric Genetics, 150B(4), 545-553.

Kodsi, M. H., \& Swerdlow, N. R. (1995). Ventral pallidal GABA-A receptors regulate prepulse inhibition of acoustic startle. Brain Research, 684(1), 26-35.

Lord, C., Rutter, M., DiLavore, P. C., \& Risi, S. (2002). Autism diagnostic observation schedule. Los Angeles: Western Psychological Services.

Lord, C., Rutter, M., \& Le Couteur, A. (1994). Autism diagnostic interview-revised: A revised version of a diagnostic interview for caregivers of individuals with possible pervasive developmental disorders. Journal of Autism and Developmental Disorders, 24, 659-685.

McAlonan, G. M., Daly, E., Kumari, V., Critchley, H. D., van Amelsvoort, T., Suckling, J., et al. (2002). Brain anatomy and sensorimotor gating in Asperger's syndrome. Brain, 125(Pt 7), 1594-1606.

McBride, S. M., Choi, C. H., Wang, Y., Liebelt, D., Braunstein, E., Ferreiro, D., et al. (2005). Pharmacological rescue of synaptic plasticity, courtship behavior, and mushroom body defects in a Drosophila model of fragile X syndrome. Neuron, 45(5), 753-764.
Ornitz, E. M., Lane, S. J., Sugiyama, T., \& de Traversay, J. (1993). Startle modulation studies in autism. Journal of Autism and Developmental Disorders, 23(4), 619-637.

Perry, W., Minassian, A., Lopez, B., Maron, L., \& Lincoln, A. (2007). Sensorimotor gating deficits in adults with autism. Biological Psychiatry, 61(4), 482-486.

Reiss, A. L., \& Freund, L. (1992). Behavioral phenotype of fragile X syndrome: DSM-III-R autistic behavior in male children. American Journal of Medical Genetics, 43(1-2), 35-46.

Rogers, S. J., Wehner, E. A., \& Hagerman, R. J. (2001). The behavioral phenotype in fragile X: Symptoms of Autism in very young children with fragile $\mathrm{X}$ syndrome, idiopathic autism, and other developmental disorders. Journal of Developmental and Behavioral Pediatrics, 22(6), 409-417.

Rutter, M., Bailey, A., Berument, S. K., Lord, C., \& Pickles, A. (2003). Social Communication Questionniare. Western Psychological Services.

Schmajuk, N. A., \& Larrauri, J. A. (2005). Neural network model of prepulse inhibition. Behavioral Neuroscience, 119(6), 15461562.

Tassone, F., Pan, R., Amiri, K., Taylor, A. K., \& Hagerman, P. J. (2008). A rapid polymerase chain reaction-based screening method for identification of all expanded alleles of the fragile $\mathrm{X}$ (FMR1) gene in newborn and high-risk populations. The Journal of Molecular Diagnostics, 10(1), 43-49.

Wassink, T. H., Piven, J., \& Patil, S. R. (2001). Chromosomal abnormalities in a clinic sample of individuals with autistic disorder. Psychiatric Genetics, 11(2), 57-63.

Wolf, R., Paelchen, K., Matzke, K., Dobrowolny, H., Bogerts, B., \& Schwegler, H. (2007). Acute or subchronic clozapine treatment does not ameliorate prepulse inhibition (PPI) deficits in CPB-K mice with low levels of hippocampal NMDA receptor density. Psychopharmacology (Berl), 194(1), 93-102.

Yan, Q. J., Rammal, M., Tranfaglia, M., \& Bauchwitz, R. P. (2005), Suppression of two major Fragile X Syndrome mouse model phenotypes by the mGluR5 antagonist MPEP. Neuropharmacology, 49(7), 1053-1066.

Zou, D., Huang, J., Wu, X., \& Li, L. (2007). Metabotropic glutamate subtype 5 receptors modulate fear-conditioning induced enhancement of prepulse inhibition in rats. Neuropharmacology, $52(2), 476-486$. 